\title{
Strategi pemanfaatan Palm Oil Mill Effluent (POME) sebagai sumber energi berkelanjutan di pabrik kelapa sawit PT. Meridan Sejati Surya Plantation Kabupaten Siak
}

\author{
Antoni $^{1}$, Yusni Ikhwan Siregar ${ }^{2}$, Suwondo ${ }^{2}$ \\ ${ }^{1}$ Environment Officer di First Resources Group \\ ${ }^{2}$ Pascasarjana Ilmu Lingkungan Program Pascasarjana Universitas Riau \\ *Correspondent email : antoni.environment@gmail.com
}

\begin{abstract}
The development of the palm oil industry in Indonesia is growing rapidly, including the increasing number of palm oil processing factories and their liquid waste which has an impact on increasing the amount of greenhouse gases through methane gas. This research was conducted to determine the strategy in utilizing the effluent palm oil mill as a sustainable energy source in the palm oil mill of PT. MSSP of Siak Regency. Utilization of palm oil mill effluent as biogas fuel is carried out using covered lagoon reactor pond technology and serves to reduce the emission value of 1,365.90 tons of $\mathrm{CH}_{4}$ during 2019 and to function in economic efficiency from the use of sustainable energy or biogas for companies by Rp. 8,109,598,450 and socially functioning for employees and the community around PT. MSSP is a positive perception, both in lightening the work of employees and reducing the will in community settlements. The strategy carried out in the utilization of palm oil mill effluent as a sustainable energy source at PT. MSSP aims at good and proper management and application. The strategy was formulated in the SWOT analysis by compiling strengths, weaknesses, opportunities and threats in the application of the utilization of palm oil mill effluent as a sustainable energy source.

Keywords: Strategy; Palm Oil Mill Effluent; Biogas, Reactor Pond; Covered Lagoon; Emission; Methane gas; Green Houses Gas
\end{abstract}

Perkembangan industri kelapa sawit di Indonesia semakin pesat, baik peningkatan luas lahan kelapa sawit maupun peningkatan jumlah pabrik pengolahan kelapa sawit. Secara khusus di Provinsi Riau yang memiliki luas areal perkebunan sebesar 2.423.801 hektar dan produksi kelapa sawit sebanyak 7.779.659 ton tandan buah segar (TBS) selama tahun 2017 (BPS Riau, 2018). Salah satu Kabupaten di Provinsi Riau yang memiliki perkebunan kelapa sawit yang cukup luas adalah Kabupaten Siak dengan luas areal perkebunan sebesar 324.216 hektar dan produksi TBS sebesar 1.093.407 ton selama tahun 2017 (BPS Riau, 2018).

Perkebunan kelapa sawit terdiri dari pabrik kelapa sawit sebagai integrasi dalam pengolahan tandan buah segar (TBS) kelapa sawit menjadi crude palm oil (CPO), dan peningkatan perkebunan kelapa sawit dapat menimbulkan dampak positif maupun dampak negatif, diantara dampak positif tersebut adalah meningkatkan pendapatan masyarakat, meningkatkan penerimaan devisa negara, meningkatkan lapangan kerja, serta menghasilkan produk yang memiliki nilai jual ekonomis tinggi. Sedangkan, salah satu dari dampak negatifnya adalah menghasilkan limbah yang diantaranya adalah limbah padat dan limbah cair (Widhiastuti et al, 2006).

Limbah cair hasil pengolahan tandan buah segar kelapa sawit merupakan salah satu limbah yang memiliki pengaruh cukup besar terhadap lingkungan karena kandungan Biologycal Oxygen Demand (BOD) dan Chemical Oxygen Demand (COD) didalamnya (Irwansyah et al., 2017). Oleh karena itu, limbah cair kelapa sawit harus diolah dan dimanfaatkan semaksimal mungkin agar tidak menjadi sumber pencemar lingkungan baik pencemaran air maupun pencemaran tanah.

Limbah cair kelapa sawit merupakan limbah yang berpotensi sebagai pupuk organik maupun dijadikan sebagai Energi Baru Terbarukan (EBT) yang diperoleh dari pengolahan limbah yang baik yang dapat dimanfaatkan sebagai bahan bakar biogas. Limbah cair kelapa sawit atau Palm Oil Mill Effluent (POME) memiliki potensi energi yang tinggi, namun pada umumnya belum dimanfaatkan secara optimal.

Limbah cair kelapa sawit atau Palm Oil Mill Effluent (POME) dapat dimanfaatkan sebagai sumber energi atau bahan bakar dengan menggunakan teknologi penangkapan gas metan atau methane capture seperti Lagoon Covered. Teknologi ini dilakukan dengan menutup kolam limbah konvensional dengan bahan reinforced polypropylene sehingga berfungsi sebagai anaerobic digester dan biogas akan terkumpul di dalam cover. Dengan teknologi ini, akan dihasilkan biogas sebanyak $\pm 20 \mathrm{~m}^{3} /$ ton TBS. Jika kapasitas PKS sebesar 30 ton TBS/jam akan menghasilkan biogas $\pm 600 \mathrm{~m}^{3} /$ ton TBS, atau setara dengan energi sebesar 
$3.720 \mathrm{kWh}$. Jika energi tersebut digunakan untuk listrik dengan menggunakan gas engine (efisiensi 35\%) maka akan dapat dibangkitkan listrik sebesar $1.302 \mathrm{kWh}$ atau 1,3 Mega Watt (Alkusma et al., 2016).

Namun, dalam proses pemanfaatan POME sebagai sumber energi atau bahan bakar ditemukan permasalahan-permasalahan yang menghambat dan mengganggu proses dalam penerapan pemanfaatan POME sebagai sumber energi atau bahan bakar, seperti mahalnya biaya teknologi yang digunakan untuk proses pemanfaatan POME sebagai sumber energi. Permasalahan lainnya adalah kurangnya pengetahuan dan kemampuan Sumber Daya Manusia (SDM) atau karyawan yang menguasai teknologi baru atau modern yang digunakan dalam proses pemanfaatan POME sebagai sumber energi di pabrik pengolahan kelapa sawit. Pemanfaatan POME sebagai sumber energi juga mengharuskan penggunaan lahan yang cukup luas, sehingga ini menjadi permasalahan bagi perusahaan dalam proses penerapan di PKS (Ade $e t$ al., 2015).

Penelitian ini bertujuan untuk menganalisis fungsi ekologi POME sebagai sumber energi berkelanjutan, menganalisis fungsi sosial dan ekonomi POME sebagai sumber energi berkelanjutan, dan menyusun strategi-strategi untuk pemanfaatan POME sebagai sumber energi berkelanjutan.

\section{METODE PENELITIAN}

Penelitian ini dilaksanakan pada bulan April sampai Juli Tahun 2020 yang berlokasi di PT. Meridan Sejati Surya Plantation Desa Maredan Kecamatan Tualang Kabupaten Siak Provinsi Riau pada lokasi Instalasi Pengolahan Air Limbah (IPAL), Pabrik Kelapa Sawit (PKS) dan lokasi Biogas Methane Capture. Metode yang digunakan dalam penelitian ini adalah adalah metode survei dan wawancara. Teknik pengumpulan data dalam penelitian ini menggunakan kunjungan secara langsung melihat proses penggunaan biogas menjadi bahan bakar untuk pengolahan PKS di PT. MSSP. Kemudian dilakukan wawancara kepada para pekerja di PKS seperti asisten pabrik untuk mengetahui proses yang ada.

Populasi dalam penelitian ini adalah Pabrik Kelapa Sawit PT. Meridan Sejati Surya Plantation yang berada di Desa Maredan Kecamatan Tualang Kabupaten Siak. Sampel dalam penelitian ini adalah 7 orang, diantaranya ada 4 orang karyawan, 2 orang masyarakat dan 1 orang staff Pegawai Negeri Sipil (PNS) Dinas Lingkungan Hidup dan Kehutanan (DLHK). Pengambilan sampel dilakukan dengan metode snowball sampling atau sampling yang dilakukan dengan pendekatan untuk menemukan informan-informan kunci (key informan) yang memiliki banyak informasi. Dengan menggunakan pendekatan ini, responden yang diwawancarai atau yang diminta informasi adalah responden yang mengerti dengan ruang lingkup penelitian (Patton, 1990).

Analisis data untuk fungsi ekologi yang dilakukan yaitu untuk mengetahui penurunan kualitas air limbah berupa perhitungan data untuk mengetahui penurunan nilai parameter kualitas air limbah sebelum (inlet) dan sesudah (outlet) dilakukan proses pembentukan biogas, kemudian untuk mengetahui penurunan kualitas udara emisi gas metan $\left(\mathrm{CH}_{4}\right)$ berupa perhitungan menggunakan kalkulator Green House Gasses RSPO untuk mengetahui pengurangan emisi gas metan, kemudian data disajikan dan ditabulasikan dalam bentuk tabel, grafik atau gambar. Sedangkan untuk penentuan strategi, dilakukan dengan analisis SWOT.

\section{HASIL DAN PEMBAHASAN}

\section{Pengolahan Limbah Cair Kelapa Sawit Menjadi Bahan Bakar Biogas atau Sumber Energi Berkelanjutan}

Pengolahan limbah cair kelapa sawit menjadi biogas di PT. Meridan Sejati Surya Plantation dilakukan dengan menggunakan teknologi covered lagoon atau kolam reaktor dengan lapisan penangkap biogas menggunakan bahan High Density Poly Ethylene (HDPE). Adapun proses pengolahan limbah cair kelapa sawit menjadi biogas melalui kolam homogenasi yang berfungsi untuk mengumpulkan dan mengaduk limbah agar homogen, feeding pump yang berfungsi untuk memberikan umpan atau mengirimkan limbah ke kolam reaktor, kolam reaktor yang berfungsi untuk menampung limbah cair kelapa sawit untuk proses pembentukan biogas, mixing pump yang berfungsi untuk mengaduk air limbah yang ada di dalam kolam reaktor agar air limbah di dalam kolam reaktor tetap homogen, digastate pump atau pompa lumpur yang berfungsi untuk menghisap dan mengangkat sludge atau lumpur yang ada di kolam reaktor dan dipompa ke kolam limbah, treated effluent overflow pit yang berfungsi sebagai saluran untuk mengangkat atau mengeluarkan air limbah sisa proses pembentukan biogas dan dialirkan ke kolam limbah, gas return blower yang berfungsi untuk mengembalikan atau mengirimkan kembali gas ke kolam reaktor apabila tekanan gas di kolam reaktor turun saat akan dikirimkan ke boiler, flare blower adalah 


\section{ZONA}

Jurnal Lingkungan

ISSN : 2502-6496 (Print)

pompa yang digunakan untuk memompa gas dari kolam reaktor ke unit pengolahan atau boiler, burner yang berfungsi sebagai pembakaran biogas menjadi api, dan boiler adalah unit pengolahan atau ketel uap yang menerima sumber bahan bakar biogas yang digunakan untuk proses pengolahan pabrik seperti perebusan tandan buah segar kelapa sawit. Dari hasil jumlah limbah kelapa sawit yang diolah menjadi biogas dan biogas yang dihasilkan dari proses pembentukan tersebut terdapat pada Tabel 1 .

Tabel 1. Jumlah Limbah yang Dimanfaatkan untuk Pembentukan Biogas dan Jumlah Biogas yang Dihasilkan

\begin{tabular}{ccccc}
\hline No. & Bulan & $\begin{array}{c}\text { Limbah yang } \\
\text { Dimanfaatkan } \mathbf{( \mathbf { M } ^ { 3 } )}\end{array}$ & $\begin{array}{c}\text { Biogas yang } \\
\left.\text { Dihasilkan } \mathbf{( M}^{\mathbf{3}}\right)\end{array}$ & Perbandingan \\
\hline 1. & Januari & 12.698 & 361.146 & 28,44 \\
2. & Februari & 10.177 & 292.273 & 28,89 \\
3. & Maret & 11.635 & 339.120 & 29,15 \\
4. & April & 9.317 & 252.631 & 27,11 \\
5. & Mei & 10.493 & 317.817 & 30,29 \\
6. & Juni & 11.523 & 333.679 & 28,96 \\
7. & Juli & 14.666 & 391.693 & 26,71 \\
8. & Agustus & 13.718 & 393.465 & 28,68 \\
9. & September & 13.454 & 407.902 & 30,32 \\
10. & Oktober & 15.396 & 450.655 & 29,27 \\
11. & November & 9.788 & 348.238 & 35,58 \\
12. & Desember & 8.195 & 283.742 & 34,62 \\
\hline & Total & $\mathbf{1 4 1 . 0 6 0}$ & $\mathbf{4 . 1 7 2 . 3 6 1}$ & $\mathbf{2 9 , 8 2}$ \\
\hline
\end{tabular}

Dari data jumlah yang dimanfaatkan untuk penangakapan gas metan dan mebentuk bahan bakar biogas atau sumber energi terlihat bahwa total limbah yang dimanfaatkan selama Tahun 2019 adalah sebesar $141.060 \mathrm{M}^{3}$ dan total biogas yang dihasilkan adalah sebesar $4.172 .361 \mathrm{~m}^{3}$ dengan rata-rata perbandingan antara limbah yang dimanfaatakan dengan biogas yang dihasilkan yaitu dalam $1 \mathrm{~m}^{3} \mathrm{limbah}$ cair kelapa sawit menghasilkan $29,82 \mathrm{~m}^{3}$ biogas. Hal ini sesuai dengan penelitian yang dilakukan oleh Safrizal (2015), yang menyatakan bahwa dengan teknologi covered lagoon, akan dihasilkan biogas sebanyak $\pm 20 \mathrm{~m}^{3} /$ ton TBS, dimana dalam 1 ton TBS dapat menghasilkan $0,7-1 \mathrm{~m}^{3}$ limbah cair.

\section{Penurunan Nilai Emisi Gas Metan $\left(\mathrm{CH}_{4}\right)$}

Gas metan $\left(\mathrm{CH}_{4}\right)$ adalah gas hidrokarbon yang sebagian besar berasal dari alam yang dihasilkan oleh dekomposisi anaerobik bahan organik. Proses pemanfaatan limbah cair kelapa sawit sebagai sumber energi atau bahan bakar biogas berperan dalam menurunkan nilai emisi gas metan. PT. MSSP telah memanfaatkan limbah cair sebagai sumber energi atau bahan bakar biogas dengan menggunakan teknologi biogas kolam reaktor covered lagoon dan menghasilkan kandungan gas metan seperti pada Tabel 2.

Tabel 2. Kandungan Gas Metan yang Dihasilkan dari Proses Kolam Reaktor

\begin{tabular}{ccc}
\hline No. & Bulan & Kandungan Gas Metan (\%) \\
\hline 1. & Januari & 58 \\
2. & Februari & 57 \\
3. & Maret & 57 \\
4. & April & 56 \\
5. & Mei & 57 \\
6. & Juni & 57 \\
7. & Juli & 58 \\
8. & Agustus & 59 \\
9. & September & 58 \\
10. & Oktober & 57 \\
11. & November & 57 \\
12. & Desember & 57 \\
\hline & Rata-rata & $\mathbf{5 7 , 3}$
\end{tabular}

Berdasarkan data dari gas analyzer biogas PT. MSSP diatas, dapat dilihat bahwa nilai gas metan yang terkandung dari hasil pembentukan biogas menggunakan teknologi covered lagoon diperoleh hasil rata-rata 
di Tahun 2019 yaitu sebesar 57,3\%. Kandungan gas rata-rata yang dihasilkan merupakan kandungan gas yang dapat digunakan sebagai bahan bakar biogas atau sumber energi pada boiler di PKS PT. MSSP. Hal ini sesuai dengan penelitian yang dilakukan oleh Safrizal (2015), yang menyatakan bahwa apabila kandungan gas metan dalam biogas lebih dari 50\%, biogas tersebut layak digunakan sebagai bahan bakar karena bersifat mudah terbakar.

Sementara itu, dari hasil pemanfaatan limbah cair kelapa sawit sebagai sumber energi atau bahan bakar biogas menunjukkan adanya penurunan nilai emisi gas metan dengan melakukan perhitungan menggunakan kalkulator Gas Rumah Kaca (GRK) Roundtable Sustainable Palm Oil (RSPO). Perhitungan penurunan nilai emisi dilakukan dengan menghitung penurunan Chemical Oxygen Demand (COD) selama periode Tahun 2019.

Berdasarkan data yang diperoleh dengan melakukan perhitungan menggunakan kalkukator Gas Rumah Kaca (GRK) Roundtable Sustainable Palm Oil (RSPO) diperoleh hasil bahwa jumlah emisi yang terdapat pada limbah cair kelapa sawit PT. MSSP selama tahun 2019 adalah sebesar 1.512,65 ton $\mathrm{CH}_{4}$. Jumlah ini diperoleh dengan menghitung jumlah produksi limbah cair selama Tahun 2019 dengan nilai COD yang terhitung selama Tahun 2019 sesuai dengan ketentuan data pada kalkulator GRK RSPO. Setelah melalui proses penangkapan gas metan menggunakan teknologi kolam reaktor covered lagoon dan dimanfaatkan menjadi sumber energi atau bahan bakar biogas diperoleh hasil bahwa telah terjadi penurunan nilai emisi gas metan sebesar 1.365,90 ton $\mathrm{CH}_{4}$ menjadi 246,74 ton $\mathrm{CH}_{4}$ selama Tahun 2019 . Hal ini menunjukkan bahwa penggunaan teknologi biogas kolam reaktor covered lagoon dalam memanfaatkan POME sebagai sumber energi atau bahan bakar di PT. MSSP berhasil melakukan penurunan nilai emisi gas metan dengan rata-rata penurunan sebesar 90,43\% selama Tahun 2019. Nilai penurunan emisi gas metan pada Tahun 2019 terdapat pada Tabel 3.

Tabel 3. Penurunan Nilai Emisi Gas Metan Berdasarkan Kalkulator GRK RSPO

\begin{tabular}{cccccc}
\hline No. & Bulan & $\begin{array}{c}\text { Nilai Emisi } \\
\text { Sebelum } \\
\text { Kolam } \\
\text { Reaktor (ton) }\end{array}$ & $\begin{array}{c}\text { Nilai Emisi } \\
\text { Setelah Kolam } \\
\text { Reaktor (ton) }\end{array}$ & $\begin{array}{c}\text { Nilai } \\
\text { Penurunan } \\
\text { Emisi (ton } \\
\mathbf{C H}_{4} \text { ) }\end{array}$ & $\begin{array}{c}\text { Penurunan Gas } \\
\text { Metan (\%) }\end{array}$ \\
\hline 1. & Januari & 93,83 & 7,59 & 86,24 & 91,91 \\
2. & Februari & 71,89 & 7,1 & 64,79 & 90,12 \\
3. & Maret & 82,83 & 8,08 & 74,75 & 90,25 \\
4. & April & 71,42 & 6,94 & 64,48 & 90,28 \\
5. & Mei & 164,97 & 16,31 & 148,66 & 90,11 \\
6. & Juni & 69,86 & 6,51 & 63,35 & 90,68 \\
7. & Juli & 226,61 & 22,96 & 203,65 & 89,87 \\
8. & Agustus & 164,03 & 16,09 & 147,94 & 90,19 \\
9. & September & 230,59 & 23,39 & 207,20 & 89,86 \\
10. & Oktober & 93,98 & 7,84 & 86,14 & 91,66 \\
11. & November & 139,53 & 13,69 & 125,84 & 90,19 \\
12. & Desember & 103,11 & 10,25 & 92,86 & 90,06 \\
\hline & Total & $\mathbf{1 . 5 1 2 , 6 5}$ & $\mathbf{1 4 6 , 7 5}$ & $\mathbf{1 . 3 6 5 , 9 0}$ & $\mathbf{9 0 , 4 3}$ \\
\hline
\end{tabular}

\section{Penurunan Nilai Kualitas Air Limbah}

Penerapan pemanfaatan air limbah pabrik kelapa sawit menjadi bahan bakar biogas atau sumber energi berkelanjutan berperan dalam menurunkan nilai kualitas air limbah. Dimana hasil uji kualitas air limbah seperti parameter $\mathrm{pH}, \mathrm{BOD}, \mathrm{COD}$ dan lainnya turun setelah melewati proses penerapan penangkapan gas metan sebagai biogas. Adapaun tabel hasil uji kualitas air limbah berupa parameter BOD dan COD sebelum melewati kolam reaktor biogas atau inlet dan sesudah melewati kolam reaktor biogas atau outlet dan penurunan kualitas air limbah cair kelapa sawit di PT. MSSP terdapat pada Tabel 4. 
Tabel 4. Penurunan Kualitas Air Limbah Parameter BOD

\begin{tabular}{lllllll}
\hline No & Bulan & $\begin{array}{l}\text { BOD } \\
(\mathrm{mg} / \mathrm{L})\end{array}$ & $\begin{array}{l}\text { Inlet } \\
\text { BOD } \\
(\mathrm{mg} / \mathrm{L})\end{array}$ & $\begin{array}{l}\text { Outlet } \\
\text { Penurunan } \\
(\mathrm{mg} / \mathrm{L})\end{array}$ & $\begin{array}{l}\text { Persentase } \\
\left(\mathrm{BOD}_{\text {removal }}\right)\end{array}$ & Penurunan \\
\hline 1. & Januari & 8.135 & 3.543 & 4.592 & $56,45 \%$ & \\
2. & Februari & 7.877 & 211,4 & $7.665,6$ & $97,32 \%$ & \\
3. & Maret & 9.026 & 684,5 & $8.341,5$ & $92,42 \%$ & \\
4. & April & 8.931 & 1.127 & 7.804 & $87,38 \%$ & \\
5. & Mei & 39.460 & 1.063 & 38.397 & $97,31 \%$ & \\
6. & Juni & 3.135 & 2.200 & 935 & $29,82 \%$ & \\
7. & Juli & 44.292 & 744,9 & $43.547,1$ & $98,32 \%$ & \\
8. & Agustus & 23.354 & 402,7 & $22.951,3$ & $98,27 \%$ & \\
9. & September & 54.882 & 946,2 & $53.935,8$ & $98,27 \%$ & \\
10. & Oktober & 63.781 & 4.039 & 59.742 & $93,67 \%$ & \\
11. & November & 39.428 & 1.353 & 38.075 & $96,57 \%$ & \\
12. & Desember & 27.059 & 1.971 & 25.088 & $92,71 \%$ & \\
\hline \multicolumn{2}{l}{ Rata-rata } & 27.447 & $1.523,8$ & $25.922,9$ & $86,54 \%$ & \\
\hline
\end{tabular}

Berdasarkan data penurunan kualitas air limbah parameter BOD diatas, dapat dilihat bahwa telah terjadi penurunan nilai atau hasil uji untuk parameter BOD. Hasil uji air limbah inlet atau sebelum melalui kolam reaktor biogas diperoleh nilai rata-rata BOD sebesar $27.447 \mathrm{mg} / \mathrm{L}$ dan hasil uji air limbah outlet atau setelah melalui kolam reaktor biogas diperoleh nilai rata-rata $\mathrm{BOD}$ sebesar $1.523,8 \mathrm{mg} / \mathrm{L}$. Rata-rata penurunan nilai kualitas air limbah untuk parameter BOD di Tahun 2019 adalah sebesar 25.922,9 mg/L dengan rata-rata persentase penurunan $\mathrm{BOD}\left(\mathrm{BOD}_{\text {removal }}\right)$ sebesar $86,54 \%$, nilai persentase penurunan tertinggi terdapat pada Bulan September yaitu sebesar $98,32 \%$ dan nilai persentase penurunan terendah pada Bulan Juni yaitu sebesar 29,82\%. Grafik penurunan nilai BOD dapat dilihat pada Gambar 1.

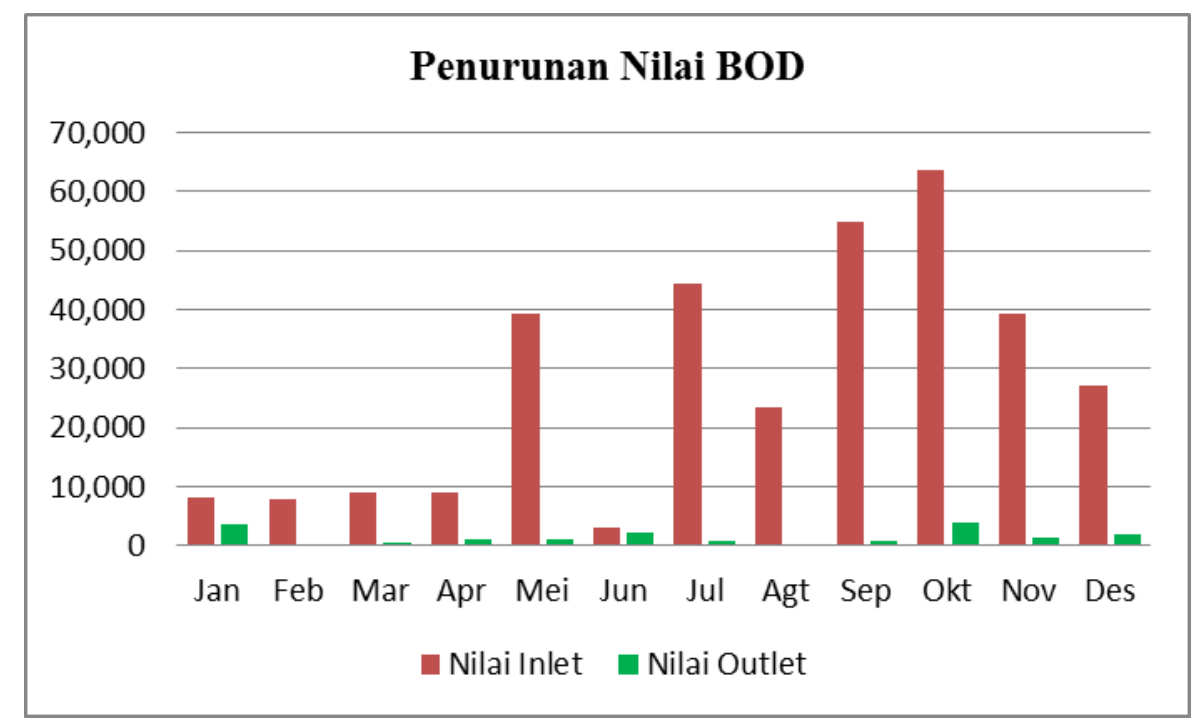

Gambar 1. Grafik Penurunan Nilai BOD

Sementara itu, parameter air limbah lainnya yaitu Chemical Oxygen Demand (COD) juga mengalami penurunan jika dibandingkan antara hasil uji outlet dan hasil uji inlet. Tabel penurunan paramater COD dapat dilihat pada Tabel 5. 
Tabel 5. Penurunan Kualitas Air Limbah Parameter COD

\begin{tabular}{llllll}
\hline No. & Bulan & $\begin{array}{l}\text { COD } \\
(\mathrm{mg} / \mathrm{L})\end{array}$ & $\begin{array}{l}\text { Inlet } \\
\text { COD } \\
(\mathrm{mg} / \mathrm{L})\end{array}$ & $\begin{array}{l}\text { Outlet } \\
\text { Penurunan } \\
(\mathrm{mg} / \mathrm{L})\end{array}$ & $\begin{array}{l}\text { Persentase Penurunan } \\
\left(\mathrm{COD}_{\text {removal }}\right)\end{array}$ \\
\hline 1. & Januari & 39.200 & 8.708 & 30.492 & $77,78 \%$ \\
2. & Februari & 35.630 & 1.792 & 33.838 & $94,97 \%$ \\
3. & Maret & 38.208 & 2.365 & 35.843 & $93,81 \%$ \\
4. & April & 37.291 & 2.462 & 34.829 & $93,39 \%$ \\
5. & Mei & 76.349 & 3.764 & 72.585 & $95,07 \%$ \\
6. & Juni & 37.120 & 3.840 & 33.280 & $89,65 \%$ \\
7. & Juli & 88.286 & 2.276 & 86.010 & $97,42 \%$ \\
8. & Agustus & 68.489 & 3.910 & 64.579 & $94,29 \%$ \\
9. & September & 91.603 & 2.265 & 89.338 & $97,53 \%$ \\
10. & Oktober & 37.088 & 7.347 & 29.741 & $80,19 \%$ \\
11. & November & 67.523 & 3.846 & 63.677 & $94,30 \%$ \\
12. & Desember & 57.587 & 2.531 & 55.056 & $95,60 \%$ \\
\hline \multicolumn{7}{l}{ Rata-rata } & $\mathbf{5 6 . 1 9 8}$ & $\mathbf{3 . 7 5 9}$ & $\mathbf{5 2 . 4 3 9}$ & $\mathbf{9 2 , 0 0 \%}$ \\
\hline
\end{tabular}

Berdasarkan data penurunan kualitas air limbah parameter COD diatas, dapat dilihat bahwa telah terjadi penurunan nilai atau hasil uji untuk parameter COD. Hasil uji air limbah inlet atau sebelum melalui kolam reaktor biogas diperoleh nilai rata-rata COD sebesar $56.198 \mathrm{mg} / \mathrm{L}$ dan hasil uji air limbah outlet atau setelah melalui kolam reaktor biogas diperoleh nilai rata-rata COD sebesar $3.759 \mathrm{mg} / \mathrm{L}$.

Rata-rata penurunan nilai kualitas air limbah untuk parameter COD di Tahun 2019 adalah sebesar $52.439 \mathrm{mg} / \mathrm{L}$ dengan rata-rata persentase penuruanan nilai $\mathrm{COD}\left(\mathrm{COD}_{\text {removal }}\right)$ sebesar $92,00 \%$, dengan nilai persentase penurunan tertinggi terdapat pada Bulan September yaitu sebesar 97,53\% dan nilai persentase penurunan terendah pada Bulan Januari yaitu sebesar 77,78\%. Hal ini sesuai dengan yang dikatakan oleh Hayashi dalam Febijanto (2010), bahwa penurunan nilai COD pada kolam anaerobik biogas dapat mengurangi COD sebesar 97,8\%. Grafik penurunan nilai COD dapat dilihat pada Gambar 2.

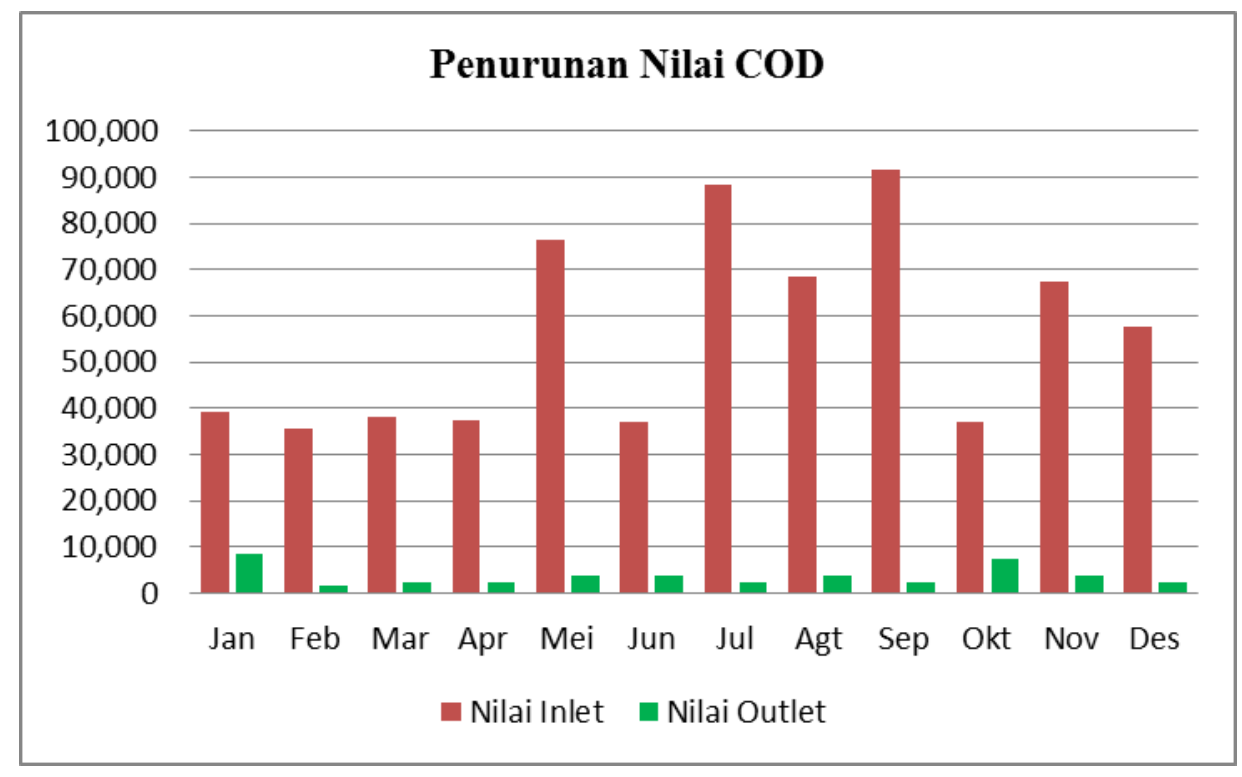

Gambar 2. Grafik Penurunan Nilai COD

\section{Fungsi Ekonomi Pemanfaatan Palm Oil Mill Effluent (POME) sebagai Sumber Energi Berkelanjutan}

Fungsi ekonomi dalam pemanfaatan palm oil mill effluent sebagai sumber energi berkelanjutan adalah adanya penurunan nilai ekonomi atau efisiensi dengan menggunakan bahan bakar biogas sebagai sumber energi boiler di pabrik kelapa sawit PT. MSSP. Nilai efisiensi energi berhubungan dengan penggunaan bahan bakar yang digunakan, dimana jumlah bahan bakar berupa cangkang sebelum dilakukannya pemanfaatan POME sebagai sumber energi atau bahan bakar lebih banyak dibandingkan dengan jumlah pemakaian setelah memanfaatkan POME menjadi sumber energi atau bahan bakar biogas. 


\section{ZONA}

Jurnal Lingkungan

ISSN : 2502-6496 (Print)

Penggunaan cangkang sebagai bahan bakar boiler untuk penggunaan sebelum biogas merupakan data penggunaan di tahun 2018 yaitu sebesar 8.658.061 kilogram, dimana PT. MSSP belum menerapkan penggunakan biogas sebagai bahan bakar atau sumber energi untuk pembangkit boiler. Sementara itu, data penggunaan cangkang sesudah penggunaan biogas merupakan data penggunaan cangkang di tahun 2019 yaitu sebesar 2.988.000 kilogram, dimana PT. MSSP sudah menggunakan biogas sebagai bahan bakar atau sumber energi, namun masih tetap menggunakan cangkang sebagai pembakaran tahapan awal agar api dapat muncul sebagai pemicu untuk melanjutkan pembakaran menggunakan biogas. Tabel penggunaan cangkang sebelum dan sesudah menggunakan biogas dapat dilihat pada Tabel 6.

Tabel 6. Penggunaan Cangkang Sebelum dan Sesudah Menggunakan Biogas

\begin{tabular}{llll}
\hline No. & Bulan & $\begin{array}{l}\text { Penggunaan } \\
\text { Sebelum Biogas }(\mathrm{Kg})\end{array}$ & $\begin{array}{l}\text { Cangkang } \\
\text { Penggunaan }\end{array} \begin{array}{c}\text { Cangkang } \\
\text { Sesudah Biogas }(\mathrm{Kg})\end{array}$ \\
\hline 1. & Januari & 726.852 & 243.000 \\
2. & Februari & 671.220 & 188.000 \\
3. & Maret & 650.418 & 217.000 \\
4. & April & 598.499 & 233.000 \\
5. & Mei & 589.655 & 260.000 \\
6. & Juni & 879.211 & 398.000 \\
7. & Juli & 886.473 & 300.000 \\
8. & Agustus & 784.458 & 273.000 \\
9. & September & 736.369 & 261.000 \\
10. & Oktober & 892.025 & 254.000 \\
11. & November & 628.815 & 187.000 \\
12. & Desember & 614.066 & 174.000 \\
\hline Total & & 8.658 .061 & 2.988 .000 \\
\hline
\end{tabular}

Rumus yang digunakan dalam perhitungan analisis ini adalah (Akhdiyatul et al, 2018) :

$\mathrm{C}_{\mathrm{os}}=\mathrm{C}_{\mathrm{f}}+\mathrm{S}+\mathrm{C}_{\mathrm{sp}}+\mathrm{C}_{\mathrm{t}}+\mathrm{C}_{\mathrm{c}}$

dengan keterangan :

$\mathrm{C}_{\mathrm{os}} \quad=$ Cost of Overall System (Biaya Sistem Pembangkit)

$\mathrm{C}_{\mathrm{f}} \quad=$ Cost of Fuel (Biaya Bahan Bakar)

$\mathrm{S} \quad=$ Sallary (Gaji Karyawan)

$\mathrm{C}_{\mathrm{sp}} \quad=$ Cost of Spare Part (Biaya Suku Cadang)

$\mathrm{C}_{\mathrm{t}} \quad=$ Cost of Technic (Biaya Penunjang Teknik)

$\mathrm{C}_{\mathrm{c}} \quad=$ Cost of Chemical (Biaya Bahan Kimia)

Berdasarkan perhitungan menggunakan Cost of Overall System $\left(\mathrm{C}_{\mathrm{os}}\right)$ atau Biaya Sistem Pembangkit sebelum PT. MSSP menggunakan biogas sebagai bahan bakar di Tahun 2018, jumlah biaya yang dikeluarkan adalah $\mathrm{C}_{\mathrm{os}}=\mathrm{C}_{\mathrm{f}}+\mathrm{S}+\mathrm{C}_{\mathrm{sp}}+\mathrm{C}_{\mathrm{t}}+\mathrm{C}_{\mathrm{c}}$ yaitu Cost of Fuel $\left(\mathrm{C}_{\mathrm{f}}\right)$ atau Biaya Bahan Bakar Rp. 12.554.188.450 + Sallary (S) atau Gaji Karyawan Rp. 59.508.000 Cost of Spare Part $\left(\mathrm{C}_{\mathrm{sp}}\right)$ atau Biaya Suku Cadang Rp. 55.000.000 + Cost of Technic $\left(\mathrm{C}_{\mathrm{t}}\right)$ atau Biaya Penunjang Teknik Rp. $122.000 .000+$ Cost of Chemical $\left(\mathrm{C}_{\mathrm{c}}\right)$ atau Biaya Bahan Kimia Rp. $0=$ Rp. 12.790.696.450.

Untuk perhitungan menggunakan Cost of Overall System $\left(\mathrm{C}_{\mathrm{os}}\right)$ atau Biaya Sistem Pembangkit setelah PT. MSSP menggunakan biogas sebagai bahan bakar di Tahun 2019, jumlah biaya yang dikeluarkan adalah $\mathrm{C}_{\mathrm{os}}=\mathrm{C}_{\mathrm{f}}+\mathrm{S}+\mathrm{C}_{\mathrm{sp}}+\mathrm{C}_{\mathrm{t}}+\mathrm{C}_{\mathrm{c}}$ yaitu Cost of Fuel $\left(\mathrm{C}_{\mathrm{f}}\right)$ atau Biaya Bahan Bakar Rp. 4.332.600.000+ Sallary (S) atau Gaji Karyawan Rp. 32.148.000 Cost of Spare Part $\left(\mathrm{C}_{\mathrm{sp}}\right)$ atau Biaya Suku Cadang $\mathrm{Rp}$. $38.500 .000+$ Cost of Technic $\left(\mathrm{C}_{\mathrm{t}}\right)$ atau Biaya Penunjang Teknik Rp. $277.850 .000+$ Cost of Chemical $\left(\mathrm{C}_{\mathrm{c}}\right)$ atau Biaya Bahan Kimia Rp. 0 = Rp. 4.681.098.000.

Nilai efisiensi energi pada pemanfaatan palm oil mill effluent sebagai sumber energi yang menggunakan biogas sebagai bahan bakar boiler pengganti cangkang memberikan penghematan pada sektor ekonomi bagi perusahaan. Penghematan yang diperoleh perusahaan adalah biaya yang dikeluarkan pada Tahun 2018 sebelum PT. MSSP menggunakan biogas atau sebelum memanfaatkan palm oil mill effluent sebagai sumber energi dikurangi dengan biaya yang dikeluarkan pada Tahun 2019 setelah PT. 
MSSP menggunakan biogas atau sebelum memanfaatkan palm oil mill effluent sebagai sumber energi yaitu Rp. 12.790.696.450 - Rp. 4.681.098.000 = Rp. 8.109.598.450.

Sehingga, dari nilai atau biaya ini terlihat bahwa telah terjadi penurunan atau efisiensi ekonomi dari sumber energi yang berbeda, dimana jumlah biaya yang dikeluarkan sebelum memanfaatkan POME sebagai sumber energi atau bahan bakar lebih besar yaitu senilai Rp. 12.790.696.450 dibandingkan dengan biaya yang dikeluarkan setelah memanfaatkan POME sebagai sumber energi atau bahan bakar biogas yaitu sebesar Rp. 4.681.098.000 dan terjadi penghematan atau efisiensi sebesar Rp. 8.109.598.450 selama Tahun 2019.

\section{Fungsi Sosial Pemanfaatan Palm Oil Mill Effluent (POME) sebagai Sumber Energi Berkelanjutan}

Untuk fungsi sosial berupa persepsi karyawan dan masyarakat yang ada di sekitar PT. MSSP, dilakukan dengan wawancara dan diperoleh hasil bahwa operator IPAL, operator boiler, karyawan teknik, asisten laboratorium dan lingkungan serta staff Dinas Lingkungan Hidup dan Kehutanan (DLHK) Provinsi Riau mengatakan bahwa pemanfaatan POME sebagai sumber energi berkelanjutan atau bahan bakar biogas memberikan keringanan dalam pekerjaan dan efisiensi dalam penggunaan bahan bakar dibanding dengan bahan bakar sebelumnya berupa cangkang.

Sementara itu, masyarakat yang di wawancara yaitu masyarakat yang ada didalam dan diluar kompleks PKS memberikan informasi bahwa penggunaan bahan bakar biogas dari pemanfaatan POME dapat menghilangkan kebauan yang tidak ada tersa lagi dibandingkan bahan bakar sebelumnya. Adapun kualitas hasil uji kebauan di PT. MSSP dapat dilihat pada Tabel 7.

Tabel 7. Hasil Uji Kebauan di PKS PT. MSSP Tahun 2019

\begin{tabular}{llllll}
\hline No. & Parameter & Satuan & Baku Mutu & Semester I & Semester II \\
\hline 1. & Hidrogen Sulfida $\left(\mathrm{H}_{2} \mathrm{~S}\right)$ & ppm & 0,02 & $<0,001$ & $<0,001$ \\
2. & Metil Merkaptan $\left(\mathrm{CH}_{3}\right.$ SH $)$ & ppm & 0,002 & $<0,002$ & $<0,002$ \\
3. & Metil Sulfida $\left(\left(\mathrm{CH}_{3}\right)_{2}\right) \mathrm{S}$ & ppm & 0,01 & $<0,006$ & $<0,006$ \\
4. & Amonia $\left(\mathrm{NH}_{3}\right)$ & ppm & 2 & 0,03 & $<0,02$ \\
5. & Stirene $\left(\mathrm{C}_{6} \mathrm{H}_{5} \mathrm{CHCH}_{3}\right)$ & ppm & 0,1 & $<0,005$ & $<0,005$ \\
\hline
\end{tabular}

Berdasarkan hasil pengujian kebauan di PKS PT. MSSP Tahun 2019, dapat dilihat bahwa seluruh parameter uji seperti, Hidrogen Sulfida $\left(\mathrm{H}_{2} \mathrm{~S}\right)$, Metil Merkaptan $\left(\mathrm{CH}_{3}-\mathrm{SH}\right)$, Metil Sulfida $\left(\left(\mathrm{CH}_{3}\right)_{2}\right) \mathrm{S}$, Amonia $\left(\mathrm{NH}_{3}\right)$, dan Stirena $\left(\mathrm{C}_{6} \mathrm{H}_{5} \mathrm{CHCH}_{3}\right)$ diperoleh hasil dibawah baku mutu yang ditetapkan oleh Keputusan Menteri Lingkungan Hidup Nomor 50 Tahun 1996 tentang Baku Tingkat Kebauan. Hal ini menunjukkan bahwa pemanfaatan limbah cair kelapa sawit sebagai sumber energi atau bahan bakar biogas di PKS PT. MSSP juga berperan dalam mengurangi kadar kebauan.

Untuk mencapai tujuan dari pemanfaatan palm oil mill effluent sebagai sumber energi berkelanjutan, maka dilakukan analisis permasalahan yang ada dari proses penerapan pemanfaatan yang ada. Analisis permasalahan kemudian diintegrasikan ke dalam analisis lingkungan, yang mencakup lingkungan internal dan lingkungan eksternal. Analisis lingkungan internal mencakup kekuatan (strengths) dan kelemahan (weaknesses), sementara analisis lingkungan eksternal mencakup peluang (opportunities) dan ancaman (threats). Analisis SWOT bertujuan untuk merumuskan alternatif strategi dalam pemanfaatan palm oil mill effluent sebagai sumber energi di PT. MSSP. 
Tabel 8. Matriks Analisis SWOT Strategi Pemanfaatan POME sebagai Sumber Energi Berkelanjutan

\begin{tabular}{|c|c|c|}
\hline Internal & $\begin{array}{l}\text { Oportunity (O) } \\
\text { 1. Adanya peluang pasar untuk membeli } \\
\text { produk ramah lingkungan } \\
\text { 2. Komitmen perusahaan untuk } \\
\text { menurunkan nilai emisi gas metan } \\
\text { 3. Komitmen perusahaan untuk tidak } \\
\text { melakukan pencemaran air } \\
\text { 4. Program pemanfaatan energi } \\
\text { berkelanjutan semakin kuat } \\
\text { 5. Mendukung program pemerintah } \\
\text { dalam rencana aksi nasional gas } \\
\text { rumah kaca }\end{array}$ & $\begin{array}{l}\text { Threats (T) } \\
\text { 1. Tidak adanya pembinaan dari } \\
\text { pemerintah setempat } \\
\text { 2. Belum adanya regulasi terkait } \\
\text { pemanfaatan POME sebagai } \\
\text { sumber energi } \\
\text { 3. Pihak ketiga dalam perawatan dan } \\
\text { perbaikan susah ditemukan } \\
\text { 4. Lembaga pelatihan operator biogas } \\
\text { masih sulit ditemukan }\end{array}$ \\
\hline $\begin{array}{l}\text { Strength (S) } \\
\text { 1. Pemanfaatan POME sebagai } \\
\text { bahan bakar biogas dapat } \\
\text { mengurangi pemakaian cangkang } \\
\text { 2. Penghematan biaya bahan bakar } \\
\text { 3. Mengurangi nilai emisi gas } \\
\text { metan }\left(\mathrm{CH}_{4}\right) \\
\text { 4. Menurunkan parameter kualitas } \\
\text { air limbah (BOD, COD) } \\
\text { 5. Mengurangi kebauan } \\
\text { 6. Kualitas bahan bakar baik } \\
\text { 7. Efisiensi tenaga kerja } \\
\text { 8. Pemanfaatan kolam limbah yang } \\
\text { tersedia }\end{array}$ & $\begin{array}{l}\text { Strategi SO } \\
\text { 1. Memanfaatkan kolam limbah yang } \\
\text { tersedia untuk kolam reaktor agar } \\
\text { tidak memerlukan lahan baru dalam } \\
\text { pembukaan kolam }\end{array}$ & $\begin{array}{l}\text { Strategi ST } \\
\text { 1. Melakukan koordinasi dengan } \\
\text { pemerintah terkait untuk menyusun } \\
\text { regulasi terkait program } \\
\text { pemanfaatan POME sebagai } \\
\text { sumber energi berkelanjutan } \\
\text { 2. Mengalokasikan biaya } \\
\text { penghematan untuk melakukan } \\
\text { pelatihan kepada operator diluar } \\
\text { daerah } \\
\text { 3. Melakukan kontrak kerjasama } \\
\text { dengan pihak ketiga yang bisa } \\
\text { melakukan perawatan dan } \\
\text { perbaikan }\end{array}$ \\
\hline $\begin{array}{l}\text { Weakness }(\mathbf{W}) \\
\text { 1. Biaya pembangunan dan } \\
\text { pemasangan alat mahal } \\
\text { 2. Tidak ada tenaga ahli dalam } \\
\text { pengoperasian } \\
\text { 3. Membutuhkan lahan yang cukup } \\
\text { luas } \\
\text { 4. Biaya perawatan mahal } \\
\text { 5. Alat rentan kerusakan dan bocor }\end{array}$ & $\begin{array}{l}\text { Strategi WO } \\
\text { 1. Mengikutsertakan operator IPAL dan } \\
\text { biogas dalam pelatihan pengoperasian } \\
\text { alat dan teknologi } \\
\text { 2. Memaksimalkan operator yang ada } \\
\text { untuk kreatif dalam belajar secara } \\
\text { mandiri dalam merawat alat dan } \\
\text { teknologi } \\
\text { 3. Membuat Standar Operasional } \\
\text { Prosedur (SOP) untuk operator agar } \\
\text { melakukan pekerjaan dengan } \\
\text { kesalahan yang minimal }\end{array}$ & $\begin{array}{l}\text { Strategi WT } \\
\text { 1. Menyediakan spare part cadangan } \\
\text { untuk alat dan teknologi agar } \\
\text { penggantian alat saat kerusakan } \\
\text { terjadi tidak lama }\end{array}$ \\
\hline
\end{tabular}

Hasil dari matriks kombinasi strategi yang diperoleh dapat diuraikan sebagai berikut :

1. Memanfaatkan kolam limbah yang tersedia untuk kolam reaktor agar tidak memerlukan lahan baru dalam pembukaan kolam

2. Mengikutsertakan operator IPAL dan biogas dalam pelatihan pengoperasian alat dan teknologi

3. Memaksimalkan operator yang ada untuk kreatif dalam belajar secara mandiri dalam merawat alat dan teknologi

4. Membuat Standar Operasional Prosedur (SOP) untuk operator agar melakukan pekerjaan dengan kesalahan yang minimal

5. Melakukan koordinasi dengan pemerintah terkait untuk menyusun regulasi terkait program pemanfaatan POME sebagai sumber energi berkelanjutan

6. Mengalokasikan biaya penghematan untuk melakukan pelatihan kepada operator diluar daerah

7. Melakukan kontrak kerjasama dengan pihak ketiga yang bisa melakukan perawatan dan perbaikan

8. Menyediakan spare part cadangan untuk alat dan teknologi agar penggantian alat saat kerusakan terjadi tidak lama. 


\section{KESIMPULAN}

Penelitian ini menunjukkan bahwa Pemanfaatan Palm Oil Mill Effluent (POME) sebagai sumber energi berkelanjutan atau bahan bakar biogas secara ekologi dapat berfungsi dalam menurunkan nilai parameter limbah seperti Biologycal Oxygen Demand (BOD) dan Chemical Oxygen Demand COD dan menurunkan nilai emisi gas metan $\left(\mathrm{CH}_{4}\right)$. Rata-rata penurunan nilai BOD limbah cair kelapa sawit yaitu sebesar $25.922,9 \mathrm{mg} / 1$ dengan persentase rata-rata yaitu sebesar $86,54 \%$, sedangkan rata-rata penurunan nilai COD limbah cair kelapa sawit yaitu sebesar $52.439 \mathrm{mg} / 1$ dengan persentase rata-rata yaitu sebesar $92 \%$. Sementara itu, penurunan nilai emisi gas metan pada proses pemanfaatan POME sebagai sumber energi adalah sebesar $1.365,90$ ton $\mathrm{CH}_{4}$, dengan persentase rata-rata penurunan yaitu sebesar $90,43 \%$. Sedangkan untuk fungsi sosial dari pemanfaatan POME sebagai sumber energi berkelanjutan adalah adanya persepsi yang positif dari karyawan dan masyarakat dan terdapat penurunan biaya bahan bakar atau efisiensi ekonomi yang dirasakan oleh perusahaan yaitu sebesar Rp. 8.109.598.450 selama Tahun 2019 untuk fungsi ekonomi. Sementara itu, berdasarkan analisis SWOT, diperoleh delapan strategi dalam pemanfaatan POME sebagai sumber energi berkelanjutan. Berdasarkan penelitian yang telah dilakukan disarankan perlunya penelitian lanjutan tentang pemanfaatan gas metan sebagai sumber listrik bagi perumahan karyawan maupun masyarakat karena potensi gas metan yang dihasilkan dari POME sangat besar, perlunya kebijakan atau aturan pemerintah yang mengatur tentang standar teknologi maupun terkait baku mutu emisi gas metan $\left(\mathrm{CH}_{4}\right)$ dari hasil pemanfaatan POME sebagai sumber energi berkelanjutan, perlu diadakannya pembinaan teknis atau pelatihan oleh perusahaan kepada operator IPAL dan biogas maupun operator boiler agar pengoperasian teknologi tepat dan berjalan dengan baik, sehingga tidak terjadi kesalahan yang dapat menyebabkan kerusakan pada alat atau teknologi, dan penerapan pemanfaatan POME sebagai sumber energi berkelanjutan atau bahan bakar biogas diharapkan dapat dilakukan oleh perusahaan-perusahaan kelapa sawit lainnya di Kabupaten Siak maupun di seluruh Indonesia, karena dapat berfungsi secara baik dalam fungsi ekologi, sosial dan ekonomi.

\section{DAFTAR PUSTAKA}

Ade, S. R., Karsiwulan, D. 2015. Konversi Palm Oil Mill Effluent Menjadi Biogas (Edisi Terjemahan). Winrock International. Jakarta

Akhdiyatul, E Radwitya., Y Chandra . 2018. Analisis Teknis dan Ekonomis dalam Penggunaan Bahan Bakar Biomassa di Pusat Listrik Tenaga Uap. Jurnal Elkha Vol. 10, No. 2: 49-55 hal.

Alkusma, Y. M., Hermawan., Hadiyanto. 2016. Pengembangan Potensi Energi Alternatif dengan Pemanfaatan Limbah Cair Kelapa Sawit sebagai Sumber Energi Baru Terbarukan di Kabupaten Kotawaringin Timur. Jurnal Ilmu Lingkungan Volume 14 Isuue 2 : 96-102 hal.

Badan Pusat Satatistik Kabupaten Siak. 2018. Kecamatan Tualang dalam Angka. Siak Sri Indrapura.

Febijanto. I. 2010. Pemanfaatan Potensi Gas Metana di Pabrik Kelapa Sawit Sei Silai PTPN 3 Sumatera Utara. Jurnal Teknik Lingkungan. Vol. 11, No. 3 : 459-474 hal.

Irwansyah, W. Y., Danial., Hiendro, A. 2017. Potensi Pemanfaatan Palm Oil Mill Effluent (POME) sebagai Bahan Baku Pembangkit Listrik Tenaga Biogas (PLTBg). Jurusan Teknik Elektro, Fakultas Teknik. Universitas Tanjungpura. Pontianak.

Patton, M. Q. 1990. Qualitative Evaluation and Research Methods. Newbury Park : Sage Psikologi Sosial Vol. 1, No. 32-47.

Safrizal. 2015. Small Renewable Energy Biogas Limbah Cair (POME) Pabrik Kelapa Sawit Menggunakan Tipe Covered Lagoon Solusi Alternatif Defisit Listrik Provinsi Riau. Jurnal Disprotek. Volume 6, Nomor 1.

Widhiastuti, R., D. Suryanto, Mukhlis dan H. Wahyuningsih. 2006. Pengaruh Pemanfaatan Limbah Cair Pabrik Pengolahan Kelapa Sawit sebagai Pupuk terhadap Biodiversitas Tanah. Jurnal Ilmiah Pertanian Kultura 41 (1) : 1-8. 